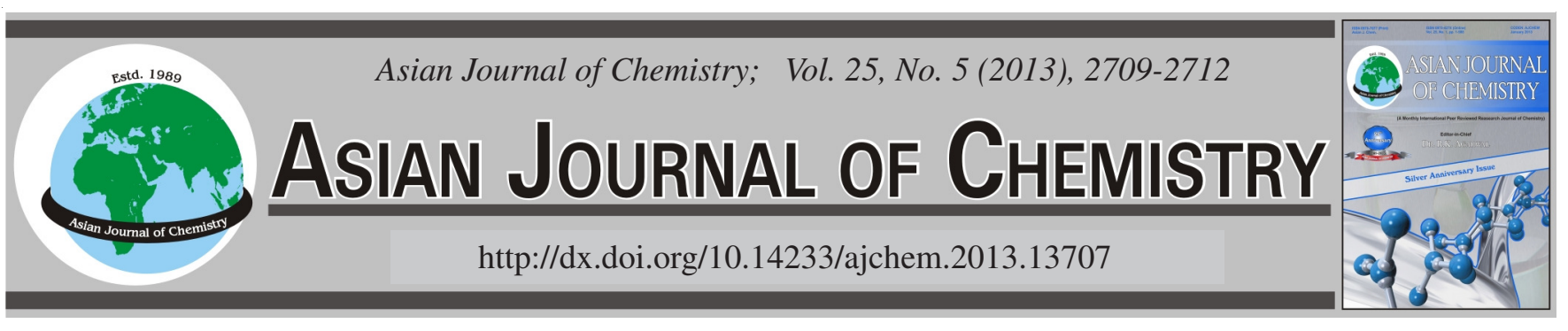

\title{
Excess Molar Properties and Viscosities of Glycerol + Water System at 298.15 to 318.15 K
}

\author{
Dawei Lan ${ }^{1}$, Lihua Liu ${ }^{1, *}$, Lining Dong ${ }^{2}$, Wenbin Li ${ }^{1}$, Qiang Li ${ }^{1}$ and Ligang Yan ${ }^{1}$
}

${ }^{1}$ College of Chemical Engineering, Inner Mongolia University of Technology, Huhhot 010051, P.R. China

${ }^{2}$ School of Electric Power, South China University of Technology, Guangzhou 510641, P.R. China

*Corresponding author: E-mail: liulihua64@imut.edu.cn; 602426646@qq.com

(Received: 10 March 2012;

Accepted: 19 November 2012)

AJC-12435

\begin{abstract}
In this study, the experimental densities for the binary system of glycerol + water at the temperature range from (298.15 to 318.15$) \mathrm{K}$ at intervals of $5 \mathrm{~K}$ are reported. Densities of pure liquids and their mixtures were determined using a bicapillary pycnometer. The viscosities were determined with an Ubbelohde capillary viscometer. The experimental results are compared with data published in the previous literatures. The density $(\rho)$ and viscosity $(\eta)$ values, the excess molar volumes $V_{m}^{\mathrm{E}}$, viscosity deviations $(\Delta \eta)$ of the experimental data, which the calculated results are fitted to a Redlich-Kister equation to obtain the coefficients and estimated the standard deviations between the experimental and calculated values. The calculated $\mathrm{V}_{\mathrm{m}}{ }^{\mathrm{E}}$ values for the glycerol + water system were negative cover whole compositions at all temperatures, while, the viscosity deviations $(\Delta \eta)$ of the aqueous glycerol solutions were positive over the major composition range.
\end{abstract}

Key Words: Glycerol, Density, Excess molar volume, Viscosity deviations.

\section{INTRODUCTION}

Sulfur dioxide $\left(\mathrm{SO}_{2}\right)$ is a hazardous gas to atmosphere, is mainly emitted from the burning of fossil fuels that contributes to acid rain and other environmental problems such as corrosion and ground-level ozone formation and is linked to several respiratory diseases ${ }^{1,2}$. The flue gas comes from the burning of fuels with high sulfur content from $0.03 \mathrm{mg} \mathrm{m}^{-3}$ in the air up to several $\mathrm{mg} \mathrm{m}^{-3}$ in a typical flue gas ${ }^{3}$. Up to now, flue gas desulfurization is one of the most effective techniques for $\mathrm{SO}_{2}$ control of the combustion of fossil fuels. The wet desulfurization method has been taken in commercial. Although the processes mainly based on limestone scrubbing and its high desulfurization efficiency, its has some disadvantages, such as high operating cost, huge magnitude of capital investment, huge magnitude water requirement and even causing secondary pollution. In recent years, the large part of organic solvents has been used in $\mathrm{SO}_{2}$ removal $^{4,5}$. In the most of organic solvents, alcohols show favourable absorption and desorption properties for acid gases in industrial processes ${ }^{6,7}$. Thus, in present research studies, great attention has been paying attention to alcohol + water systems for the $\mathrm{SO}_{2}$ scrubbing ${ }^{8-13}$.

Glycerol is an important solvent in the pharmaceutical and food industries, available as a industrial organic solvent in the removal of $\mathrm{SO}_{2}$ from flue gas ${ }^{14,15}$. Because of its favourable properties, such as low vapour pressure, low toxicity, low melting point and high chemical stability. The physical properties of glycerol + water binary system may be benefit to solubility and desorption capability for $\mathrm{SO}_{2}$. Especially, the previous literature ${ }^{16-22}$ of density $(\rho)$ and viscosity $(\eta)$ data prove that only the partly mixing properties of glycerol + water have reported. Therefore, we have to implement the measurements for densities and viscosities of glycerol + water.

In present work, the densities and viscosities of glycerol + water are presented at the temperature range of (298.15 to 318.15) K. Based on these results, the excess molar volume and the deviation of the viscosity were discussed.

\section{EXPERIMENTAL}

Analytical grade was purchased from Beijing Reagent Company. Glycerol was dried over $0.4 \mathrm{~nm}$ molecular sieves decompression filtration before measurements and through the ultrasonic model degassing just before the experiments. The purity of the sample was checked by density determination at $298.15 \mathrm{~K}$. The density of glycerol at $298.15 \mathrm{~K}$ was found to be $1.2580 \mathrm{~g} \mathrm{~cm}^{-3}$, in good agreement with the literatures ${ }^{23}$. Meanwhile, bi-distilled water and high-performance liquid chromatography (HPLC) grade ethanol were used at present work.

Measurements: The solutions of binary mixtures were prepared by mass using an electronic analytical balance (Sartorius BS 224S), which shows a precision of $\pm 0.0001 \mathrm{~g}$. The uncertainty in the mole fraction for each binary mixture was approximated to be \pm 0.0001 . 
Densities of pure liquids and their mixtures were determined using a bicapillary pycnometer having a bulb volume of $10 \mathrm{~cm}^{3}$. The volume of the pycnometer was calibrated as a function of temperature using distilled, deionized and degassed water at various temperatures of $\mathrm{T}=(298.15$ to 318.15$) \mathrm{K}$ at intervals of $5 \mathrm{~K}$. Each experimental density and viscosity value was controlled to $\pm 0.01 \mathrm{~K}$ in a thermostatically controlled and well-stirred water bath. The pycnometer filled with liquid was kept in the water bath for 20 min to accomplish thermal equilibrium. The density value of experimental was an average of at least three measurements; however, the uncertainty of the density measurement was approximated to be lower than $\pm 0.03 \%$.

The kinematic viscosity in both the pure components and their mixtures was made with a commercial capillary viscometer for has a capillary diameter of $0.90 \mathrm{~mm}$ of the Ubbelohde type, which was calibrated with bi-distilled water and ethanol (HPLC grade) at the temperatures of $(298.15,303.15,308.15$, 313.15 and 318.15$) \mathrm{K}$. The flow time was determined with a hand-held digital stopwatch capable of measuring time within $\pm 0.01 \mathrm{~s}$; furthermore, the measurements of density and viscosity were accomplished in a transparent glasswalled water bath with the thermal stability $0.01 \mathrm{~K}$.

The kinematic viscosity $(v)$ was calculated from the following equation:

$$
v=A t \frac{B}{t}
$$

where, $v$ shows the kinematic viscosity; $t$ shows its flow time of liquids; and A and B shows viscometer constants. A and B are calculated from measurements with the calibration fluids bi-distilled water and ethanol. The absolute viscosity $(\eta)$ was obtained by multiplying the determined $v$ by the measured density $(\eta=v \rho)$. Each experimental point was the average of 16 sets, which has a maximum deviation of $\pm 0.3 \%$ in the flow time.

\section{RESULTS AND DISCUSSION}

Experimental values of the densities the binary solutions of glycerol + water over the temperature range from $(298.15$ to 318.15$) \mathrm{K}$ with a step of $5 \mathrm{~K}$ throughout the whole concentration range are presented in Table-1 (Fig. 1).

Table-1 (Fig. 1) display that the density values increase with the increasing glycerol concentrations in binary solutions over the whole concentration range and the values quickly increase between $x_{1}=0$ and $x_{1}=0.2$. Moreover, under the same concentration with temperature increasing density value decreases.

The excess mole volume $\mathrm{V}_{\mathrm{m}}{ }^{\mathrm{E}}$ was calculated from density measurements according to the following equation.

$$
\mathrm{V}_{\mathrm{m}}^{\mathrm{E}}=\frac{\mathrm{x}_{1} \mathrm{M}_{1}+\mathrm{x}_{2} \mathrm{M}_{2}}{\rho_{\mathrm{m}}}-\left(\mathrm{x}_{1} \frac{\mathrm{M}_{1}}{\rho_{1}}+\mathrm{x}_{2} \frac{\mathrm{M}_{2}}{\rho_{2}}\right)
$$

where, $\rho_{\mathrm{m}}$ shows that the density of the mixture and $\mathrm{x}_{1}, \rho_{1}, \mathrm{M}_{1}$, $\mathrm{x}_{2}, \rho_{2}$ and $\mathrm{M}_{2}$ are the mole fractions, densities and molecular weights of the pure glycerol and pure water, respectively. The results of $\mathrm{V}_{\mathrm{m}}{ }^{\mathrm{E}}$ are listed in Table-2 and the dependence of $\mathrm{V}_{\mathrm{m}}{ }^{\mathrm{E}}$ at various temperatures (Fig. 2).

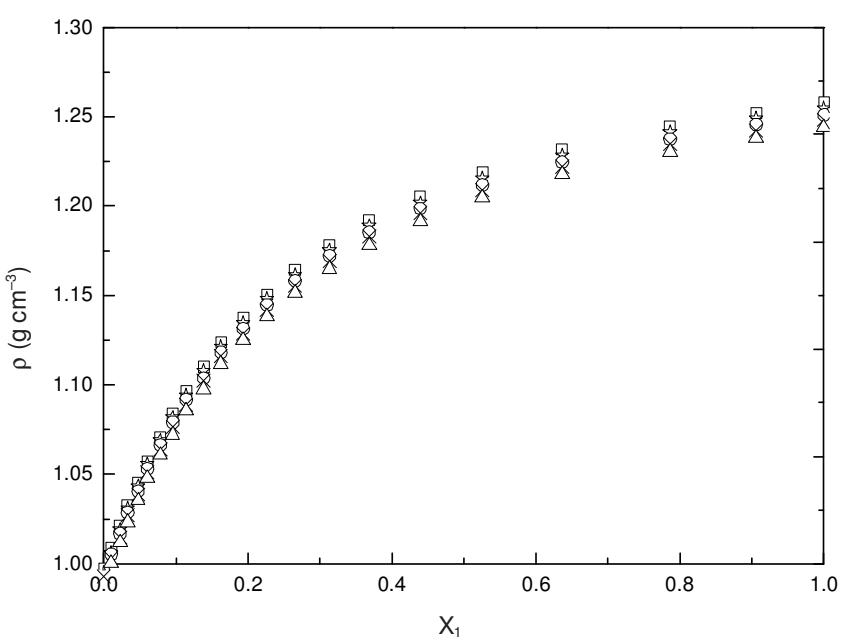

Fig. 1. Experimental densities with mole fraction for glycerol (1) + water (2): $\square, 298.15 \mathrm{~K}$; 败, $303.15 \mathrm{~K} ; 0,308.15 \mathrm{~K} ; \times, 313.15 \mathrm{~K}$; and $\triangle$, $318.15 \mathrm{~K}$

TABLE-1

EXPERIMENTAL DENSITIES ( $\rho$ ) OF GLYCEROL (1)+WATER (2)

\begin{tabular}{cccccc}
\hline & \multicolumn{5}{c}{$\rho /\left(\mathrm{g} \mathrm{cm}^{-3}\right)$} \\
\cline { 2 - 6 } $\mathrm{x}_{1}$ & $\mathrm{~T}(\mathrm{~K})=$ & $\mathrm{T}(\mathrm{K})=$ & $\mathrm{T}(\mathrm{K})=$ & $\mathrm{T}(\mathrm{K})=$ & $\mathrm{T}(\mathrm{K})=$ \\
& 298.15 & 303.15 & 308.15 & 313.15 & 318.15 \\
\hline 0.0000 & 0.9971 & 0.9950 & 0.9933 & 0.9930 & 0.9892 \\
0.0101 & 1.0087 & 1.0060 & 1.0052 & 1.0028 & 1.0004 \\
0.0220 & 1.0211 & 1.0190 & 1.0169 & 1.0147 & 1.0117 \\
0.0328 & 1.0329 & 1.0309 & 1.0287 & 1.0270 & 1.0231 \\
0.0472 & 1.0452 & 1.0433 & 1.0407 & 1.0386 & 1.0353 \\
0.0608 & 1.0574 & 1.0557 & 1.0531 & 1.0509 & 1.0478 \\
0.0782 & 1.0708 & 1.0689 & 1.0663 & 1.0639 & 1.0607 \\
0.0952 & 1.0839 & 1.0817 & 1.0790 & 1.0765 & 1.0721 \\
0.1144 & 1.0964 & 1.0942 & 1.0917 & 1.0890 & 1.0855 \\
0.1384 & 1.1102 & 1.1078 & 1.1037 & 1.1023 & 1.0975 \\
0.1627 & 1.1235 & 1.1213 & 1.1182 & 1.1161 & 1.1119 \\
0.1935 & 1.1375 & 1.1345 & 1.1315 & 1.1286 & 1.1249 \\
0.2265 & 1.1507 & 1.1479 & 1.1445 & 1.1420 & 1.1382 \\
0.2652 & 1.1644 & 1.1616 & 1.1583 & 1.1556 & 1.1514 \\
0.3128 & 1.1782 & 1.1753 & 1.1720 & 1.1690 & 1.1648 \\
0.3683 & 1.1921 & 1.1888 & 1.1853 & 1.1830 & 1.1782 \\
0.4394 & 1.2056 & 1.2019 & 1.1986 & 1.1958 & 1.1913 \\
0.5257 & 1.2188 & 1.2153 & 1.2118 & 1.2088 & 1.2046 \\
0.6364 & 1.2316 & 1.2284 & 1.2246 & 1.2220 & 1.2175 \\
0.7863 & 1.2447 & 1.2413 & 1.2374 & 1.2347 & 1.2303 \\
0.9060 & 1.2522 & 1.2490 & 1.2457 & 1.2422 & 1.2379 \\
1.0000 & 1.2580 & 1.2546 & 1.2510 & 1.2483 & 1.2440 \\
\hline
\end{tabular}

Table-2 (Fig. 2) display that the values of $\mathrm{V}_{\mathrm{m}}{ }^{\mathrm{E}}$ are negative for all the mixtures over the entire mole fraction range at all temperature. The maximum is found at approximately $\mathrm{x}_{1}=$ 0.38 , along with the increase of the temperature that the value of $\mathrm{V}_{\mathrm{m}}{ }^{\mathrm{E}}$ become less negative.

A Redlich-Kister relation was used to correlate the excess volume data according to the following equation:

$$
\mathrm{V}_{\mathrm{m}}^{\mathrm{E}}\left(\mathrm{cm}^{3} \mathrm{~mol}^{-1}\right)=\mathrm{x}_{1} \mathrm{x}_{2} \sum_{\mathrm{i}=0}^{\mathrm{n}} \mathrm{A}_{\mathrm{i}}\left(2 \mathrm{x}_{1}-1\right)^{\mathrm{i}}
$$

where, $\mathrm{x}_{1}$ shows the mole fraction of glycerol; $\mathrm{x}_{2}$ shows the mole fraction of water; and $\mathrm{A}_{\mathrm{i}}$ shows the polynomial coefficients; and $\mathrm{n}$ shows that the polynomial degree.

The standard deviation values, $\sigma$, between the calculated and experimental data according to the following equation: 


\begin{tabular}{cccccc}
\hline \multicolumn{5}{c}{ TABLE-2 } \\
\multicolumn{5}{c}{ EXCESS MOLAR VOLUMES $\left(\mathrm{V}_{\mathrm{m}}^{\mathrm{E}}\right)$ FOR } \\
\hline \multirow{5}{c}{ GLYCEROL $(1)+$ WATER $(2)$} \\
\cline { 2 - 6 } $\mathrm{x}_{1}$ & $\mathrm{~T}(\mathrm{~K})=$ & $\mathrm{T}(\mathrm{K})=$ & $\mathrm{T}(\mathrm{K})=$ & $\mathrm{T}(\mathrm{K})=$ & $\mathrm{T}(\mathrm{K})=$ \\
& 298.15 & 303.15 & 308.15 & 313.15 & 318.15 \\
\hline 0.0000 & 0.0000 & 0.0000 & 0.0000 & 0.0000 & 0.0000 \\
0.0101 & -0.0220 & -0.0113 & -0.0309 & 0.0065 & -0.0189 \\
0.0220 & -0.0413 & -0.0425 & -0.0377 & -0.0051 & -0.0216 \\
0.0328 & -0.0816 & -0.0859 & -0.0814 & -0.0601 & -0.0581 \\
0.0472 & -0.0878 & -0.0967 & -0.0832 & -0.0554 & -0.0677 \\
0.0608 & -0.1231 & -0.1366 & -0.1252 & -0.0960 & -0.1122 \\
0.0782 & -0.1443 & -0.1545 & -0.1466 & -0.1147 & -0.1305 \\
0.0952 & -0.1891 & -0.1956 & -0.1855 & -0.1519 & -0.1430 \\
0.1144 & -0.2139 & -0.2211 & -0.2184 & -0.1810 & -0.1936 \\
0.1384 & -0.2357 & -0.2407 & -0.2022 & -0.1966 & -0.1804 \\
0.1627 & -0.2758 & -0.2866 & -0.2716 & -0.2535 & -0.2494 \\
0.1935 & -0.2965 & -0.2908 & -0.2810 & -0.2426 & -0.2531 \\
0.2265 & -0.3194 & -0.3198 & -0.3019 & -0.2753 & -0.2827 \\
0.2652 & -0.3454 & -0.3492 & -0.3349 & -0.3046 & -0.3043 \\
0.3128 & -0.3560 & -0.3577 & -0.3466 & -0.3102 & -0.3121 \\
0.3683 & -0.3753 & -0.3680 & -0.3522 & -0.3414 & -0.3212 \\
0.4394 & -0.3534 & -0.3333 & -0.3267 & -0.3026 & -0.2919 \\
0.5257 & -0.3210 & -0.3092 & -0.3006 & -0.2673 & -0.2721 \\
0.6364 & -0.2522 & -0.2549 & -0.2373 & -0.2247 & -0.2164 \\
0.7863 & -0.1562 & -0.1516 & -0.1302 & -0.1212 & -0.1167 \\
0.9060 & -0.0414 & -0.0477 & -0.0613 & -0.0138 & -0.0165 \\
1.0000 & 0.0000 & 0.0000 & 0.0000 & 0.0000 & 0.0000 \\
\hline & & & & &
\end{tabular}

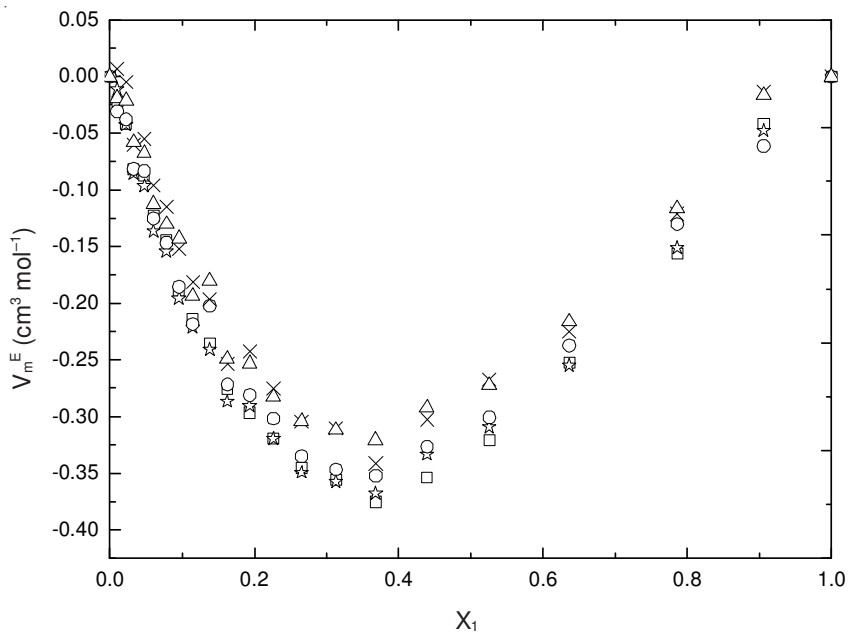

Fig. 2. Excess molar volumes with mole fraction for glycerol $(1)+$ water (2): $\square, 298.15 \mathrm{~K}$; 2 , $303.15 \mathrm{~K} ; 0,308.15 \mathrm{~K} ; \times, 313.15 \mathrm{~K}$; and $\triangle$, $318.15 \mathrm{~K}$

$$
\sigma_{\mathrm{V}_{\mathrm{m}}^{\mathrm{E}}}=\left[\Sigma\left(\mathrm{V}_{\text {calc }}^{\mathrm{E}}-\mathrm{V}_{\mathrm{m}}^{\mathrm{E}}\right)^{2} /(\mathrm{N}-\mathrm{m})\right]^{1 / 2}
$$

where, $\mathrm{N}$ shows the total number of experimental points and $m$ shows the number of $A_{i}$ coefficients considered. The coefficients $\mathrm{A}_{\mathrm{i}}$ and corresponding standard deviations (s) are listed in Table-3.

The experimental values of viscosities of the binary solutions of glycerol + water at $(298.15,303.15,308.15,313.15$ and 318.15) $\mathrm{K}$ are listed in Table-4 (Fig. 3). In all cases, along with the increase of the glycerol concentration that the value of the viscosities increased, at the same time, the viscosities decrease with the increasing temperature.
TABLE-3

COEFFICIENTS AND STANDARD DEVIATIONS OF EXCESS MOLE VOLUMES $\left(\mathrm{V}_{\mathrm{m}}{ }^{\mathrm{E}}\right)$ FOR GLYCEROL $(1)+$ WATER (2)

\begin{tabular}{ccccccc}
\hline $\mathrm{T} / \mathrm{K}$ & $\mathrm{A}_{0}$ & $\mathrm{~A}_{1}$ & $\mathrm{~A}_{2}$ & $\mathrm{~A}_{3}$ & $\mathrm{~A}_{4}$ & $\begin{array}{c}\sigma /\left(\mathrm{cm}^{3}\right. \\
\left.\mathrm{mol}^{-1}\right)\end{array}$ \\
\hline 298.15 & -1.331 & 0.808 & -0.314 & 0.205 & 0.486 & 0.0074 \\
303.15 & -1.436 & 0.670 & -0.546 & 0.313 & 0.515 & 0.0088 \\
308.15 & -1.254 & 0.913 & -0.047 & -0.136 & -0.213 & 0.0117 \\
313.15 & -1.139 & 0.736 & -0.609 & 0.256 & 1.435 & 0.0144 \\
318.15 & -1.119 & 0.730 & -0.481 & 0.325 & 1.053 & 0.0112 \\
\hline
\end{tabular}

\begin{tabular}{|c|c|c|c|c|c|}
\hline \multirow[b]{3}{*}{$\mathrm{X}_{1}$} & \multicolumn{4}{|c|}{$\begin{array}{c}\text { TABLE-4 } \\
\text { EXPERIMENTAL VISCOSITIES ( } \eta) \text { OF } \\
\text { GLYCEROL }(1)+\text { WATER }(2)\end{array}$} & \\
\hline & \multicolumn{5}{|c|}{$\eta /(\mathrm{mPa} s)$} \\
\hline & $\begin{array}{l}\mathrm{T}(\mathrm{K})= \\
298.15\end{array}$ & $\begin{array}{l}\mathrm{T}(\mathrm{K})= \\
303.15\end{array}$ & $\begin{array}{l}\mathrm{T}(\mathrm{K})= \\
308.15\end{array}$ & $\begin{array}{l}\mathrm{T}(\mathrm{K})= \\
313.15\end{array}$ & $\begin{array}{l}\mathrm{T}(\mathrm{K})= \\
318.15\end{array}$ \\
\hline 0.0000 & 0.893 & 0.792 & 0.723 & 0.652 & 0.596 \\
\hline 0.0101 & 0.920 & 0.828 & 0.741 & 0.677 & 0.618 \\
\hline 0.0220 & 0.957 & 0.863 & 0.779 & 0.708 & 0.647 \\
\hline 0.0328 & 1.01 & 0.907 & 0.821 & 0.741 & 0.677 \\
\hline 0.0472 & 1.08 & 0.969 & 0.875 & 0.787 & 0.718 \\
\hline 0.0608 & 1.18 & 1.05 & 0.958 & 0.847 & 0.769 \\
\hline 0.0782 & 1.32 & 1.17 & 1.06 & 0.930 & 0.840 \\
\hline 0.0952 & 1.51 & 1.31 & 1.19 & 1.03 & 0.928 \\
\hline 0.1144 & 1.75 & 1.51 & 1.36 & 1.17 & 1.05 \\
\hline 0.1384 & 2.10 & 1.79 & 1.61 & 1.36 & 1.21 \\
\hline 0.1627 & 2.58 & 2.18 & 1.95 & 1.62 & 1.43 \\
\hline 0.1935 & 3.28 & 2.73 & 2.41 & 1.98 & 1.73 \\
\hline 0.2265 & 4.33 & 3.53 & 3.09 & 2.50 & 2.16 \\
\hline 0.2652 & 5.89 & 4.75 & 4.10 & 3.28 & 2.78 \\
\hline 0.3128 & 8.48 & 6.69 & 5.71 & 4.47 & 3.73 \\
\hline 0.3683 & 13.0 & 10.0 & 8.24 & 6.35 & 5.23 \\
\hline 0.4394 & 21.2 & 15.4 & 12.5 & 9.46 & 7.61 \\
\hline 0.5257 & 36.6 & 26.1 & 20.6 & 15.1 & 11.9 \\
\hline 0.6364 & 70.0 & 47.8 & 37.0 & 26.4 & 20.2 \\
\hline 0.7863 & 153.0 & 101.1 & 74.6 & 51.4 & 38.1 \\
\hline 0.9060 & 259.1 & 170.1 & 119.8 & 80.7 & 58.5 \\
\hline 1.0000 & 396.5 & 253.9 & 178.8 & 118.6 & 84.2 \\
\hline
\end{tabular}

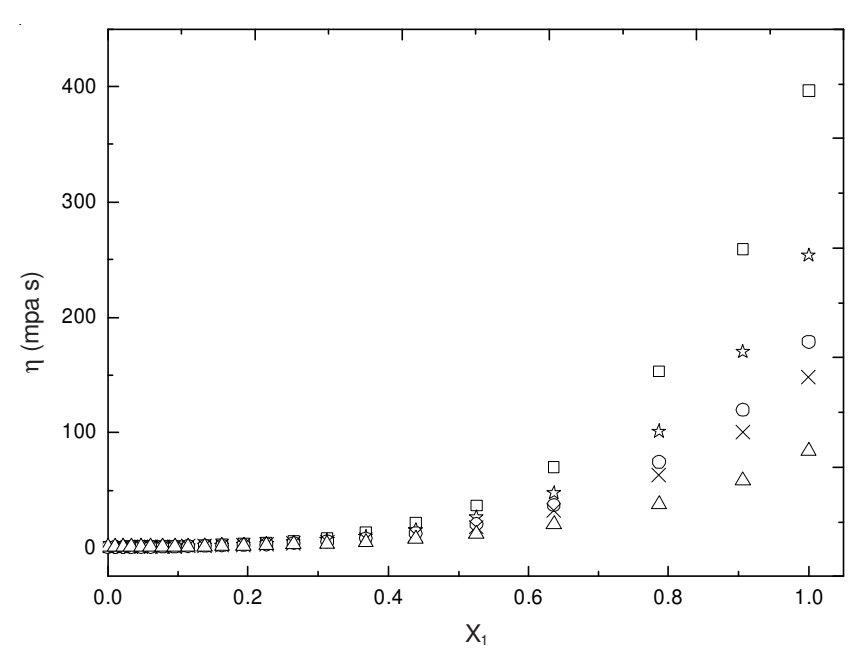

Fig. 3. Experimental viscosities with mole fraction for glycerol $(1)+$ water (2): $\square, 298.15 \mathrm{~K}$; is, $303.15 \mathrm{~K}$;, $308.15 \mathrm{~K} ; \times, 313.15 \mathrm{~K}$; and $\triangle$, $318.15 \mathrm{~K}$

The experimental values of $\eta$ for the various mixtures have been used to calculate the viscosity deviation, $\Delta \eta$, which is obtained by the following equation.

$$
\Delta \eta=\eta-\left(x_{1} \eta_{1}+x_{2} \eta_{2}\right)
$$


where, $\eta$ show the viscosity of the mixture; $\eta_{1}$ and $\eta_{2}$ are respectively show the viscosities of pure glycerol and pure water and $\mathrm{x}_{1}$ and $\mathrm{x}_{2}$ are the mole fractions of the pure components. The results of the viscosity deviation $(\Delta \eta)$ are listed in Table-5 (Fig. 4).

\begin{tabular}{cccccc}
\multicolumn{5}{c}{ TABLE-5 } \\
\multicolumn{5}{c}{ VISCOSITY DEVIATIONS $(\Delta \eta)$ FOR } \\
\hline \multicolumn{5}{c}{ GLYCEROL $(1)+$ WATER $(2)$} \\
\cline { 2 - 6 } $\mathrm{x}_{1}$ & $\mathrm{~T}(\mathrm{~K})=$ & $\mathrm{T}(\mathrm{K})=$ & $\mathrm{T}(\mathrm{mPa})=$ & $\mathrm{T}(\mathrm{K})=$ & $\mathrm{T}(\mathrm{K})=$ \\
& 298.15 & 303.15 & 308.15 & 313.15 & 318.15 \\
\hline 0.0000 & 0.000 & 0.000 & 0.000 & 0.000 & 0.000 \\
0.0101 & 0.026 & 0.020 & 0.018 & 0.021 & 0.022 \\
0.0220 & 0.062 & 0.054 & 0.056 & 0.050 & 0.050 \\
0.0328 & 0.112 & 0.096 & 0.096 & 0.082 & 0.079 \\
0.0472 & 0.179 & 0.154 & 0.146 & 0.125 & 0.116 \\
0.0608 & 0.270 & 0.227 & 0.222 & 0.179 & 0.162 \\
0.0782 & 0.393 & 0.332 & 0.309 & 0.253 & 0.225 \\
0.0952 & 0.557 & 0.456 & 0.422 & 0.340 & 0.300 \\
0.1144 & 0.759 & 0.619 & 0.567 & 0.453 & 0.398 \\
0.1384 & 1.036 & 0.845 & 0.765 & 0.606 & 0.526 \\
0.1627 & 1.42 & 1.15 & 1.03 & 0.809 & 0.698 \\
0.1935 & 1.92 & 1.55 & 1.36 & 1.07 & 0.91 \\
0.2265 & 2.66 & 2.10 & 1.83 & 1.43 & 1.20 \\
0.2652 & 3.66 & 2.89 & 2.48 & 1.92 & 1.61 \\
0.3128 & 5.21 & 4.04 & 3.42 & 2.61 & 2.15 \\
0.3683 & 7.67 & 5.81 & 4.75 & 3.59 & 2.92 \\
0.4394 & 11.4 & 8.18 & 6.62 & 4.93 & 3.94 \\
0.5257 & 16.9 & 12.0 & 9.43 & 6.87 & 5.37 \\
0.6364 & 25.1 & 17.1 & 13.1 & 9.36 & 7.12 \\
0.7863 & 32.5 & 21.4 & 15.7 & 10.8 & 8.01 \\
0.9060 & 24.2 & 15.9 & 11.2 & 7.52 & 5.44 \\
1.0000 & 0.0000 & 0.0000 & 0.0000 & 0.0000 & 0.0000 \\
\hline & \multicolumn{5}{c}{}
\end{tabular}

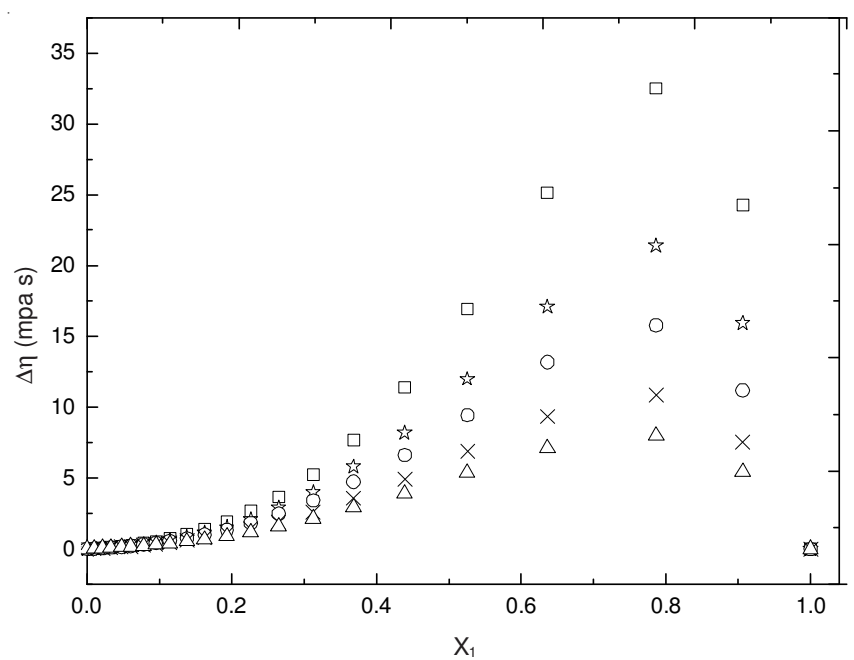

Fig. 4. Viscosity deviations with mole fraction for glycerol (1) + water (2): $\square, 298.15 \mathrm{~K}$; $2,303.15 \mathrm{~K} ; \circ, 308.15 \mathrm{~K} ; \times, 313.15 \mathrm{~K}$; and $\triangle$, $318.15 \mathrm{~K}$

Fig. 4 shows that the large of the $\Delta \eta$ values are positive over the main composition range for all mixtures in all cases. The $\Delta \eta$ versus $x_{1}$ curves shift toward the water-rich region and the observed results are similar to the $\mathrm{V}_{\mathrm{m}}^{\mathrm{E}}$ results. The viscosity deviations, $\Delta \eta$, decrease with the increasing tempe-ratures.

The viscosity deviations, $\Delta \eta$, were also displayed by the Redlich-Kister equation as follows:

$$
\Delta \eta / m P a . s=x_{1} x_{2} \sum_{i=0}^{n} B_{i}\left(2 x_{1}-1\right)^{i}
$$

The coefficients $\mathrm{B}_{\mathrm{i}}$ and the standard deviation are presented in Table-6.

\section{TABLE-6}

COEFFICIENTS AND STANDARD DEVIATIONS OF VISCOSITY DEVIATIONS $(\Delta \eta)$ FOR GLYCEROL (1) + WATER (2)

\begin{tabular}{ccccccc}
\hline $\mathrm{T}(\mathrm{K})$ & $\mathrm{B}_{0}$ & $\mathrm{~B}_{1}$ & $\mathrm{~B}_{2}$ & $\mathrm{~B}_{3}$ & $\mathrm{~B}_{4}$ & $\sigma /\left(\mathrm{m}^{2} \cdot \mathrm{s}\right)$ \\
\hline 298.15 & 60.862 & 138.39 & 129.24 & 52.195 & 1.018 & 0.0906 \\
303.15 & 43.296 & 89.609 & 77.378 & 34.513 & 4.799 & 0.0488 \\
308.15 & 34.410 & 67.595 & 54.313 & 16.475 & -3.978 & 0.0407 \\
313.15 & 25.252 & 46.362 & 33.868 & 9.059 & -2.771 & 0.0285 \\
318.15 & 19.850 & 33.926 & 22.513 & 5.397 & -1.877 & 0.0225 \\
\hline
\end{tabular}

\section{Conclusion}

This paper reports the densities and viscosities of the binary system of aqueous glycerol solutions of the experimental data at $\mathrm{T}=(298.15$ to 318.15$) \mathrm{K}$. These data have been used to compute excess properties of the system. The calculated $\mathrm{V}_{\mathrm{m}}{ }^{\mathrm{E}}$ values for the glycerol + water system were negative at each temperatures and compositions, whereas the viscosity deviations $(\Delta \eta)$ of the aqueous glycerol solutions were positive at all temperatures and compositions.

\section{REFERENCES}

1. J.L. Llanos, A.E. Fertitta, E.S. Flores and E.J. Bottani, J. Phys. Chem. B, 107, 8448 (2003).

2. S.H. Ren, Y.C. Hou, W.Z. Wu and M.J. Jin, Ind. Eng. Chem. Res., 50, 998 (2011).

3. M. Siddiqi, A. Krissmann, J. Peters-Gerth, M. Luckas and K. Lucas, J. Chem. Thermodyn., 28, 685 (1996).

4. M.H.H. van Dam, A.S. Lamine, D. Roizard, P. Lochon and C. Roizard, Ind. Eng. Chem. Res., 36, 4628 (1997).

5. X. Esteve, A. Conesa and A. Coronas, J. Chem. Eng. Data, 48, 392 (2003).

6. C.N. Schubert and W.I. Echter, The Method of Polymer Ethylene Glycol for Removal Pllution from Gases, CN Patent 1364096A (2002).

7. J.B. Zhang, P.Y. Zhang, G.H. Chen, F. Han and X.H. Wei, J. Chem. Eng. Data, 53, 1479 (2008).

8. J.B. Zhang, G.H. Chen, P.Y. Zhang, F. Han, J.F. Wang and X.H. Wei, J. Chem. Eng. Data, 55, 1446 (2010).

9. J.B. Zhang, P.Y. Zhang, F. Han, G.H. Chen, L.W. Zhang and X.H. Wei, Ind. Eng. Chem. Res., 48, 1287 (2009).

10. J.B. Zhang, Q. Li, Z.H. Guo, K.X. Li, M.D. Xu, N. Zhang, T. Zhang and X.H. Wei, Ind. Eng. Chem. Res., 50, 674 (2011).

11. J.B. Zhang, F. Han, X.H. Wei, L.K. Shui, H. Gong and P.Y. Zhang, Ind. Eng. Chem. Res., 49, 2025 (2010).

12. J.B. Zhang, P.Y. Zhang, F. Han, G.H. Chen, R.H. Deng and X.H. Wei, J. Chem. Eng. Data, 53, 2372 (2008).

13. J.B. Zhang, F. Han, P.Y. Zhang, G.H. Chen and X.H. Wei, J. Chem. Eng. Data, 55, 959 (2010).

14. Y.G. Zheng, X.L. Chen and Y.C. Shen, Chem. Rev., 108, 5253 (2008).

15. C.W. Chiu, M.A. Dasari, W.R. Sutterlin and G.J. Suppes, Ind. Eng. Chem. Res., 45, 791 (2006).

16. M.T. Sanz, B. Blanco, S. Beltran and and J.L. Cabezas, J. Chem. Eng. Data, 46, 635 (2001).

17. C.S. Liu, K.G.H. Desai, X.X. Tang and X.G. Chen, J. Chem. Eng. Data, 50, 2061 (2005).

18. M.-C. Hu, W.-J. Zhang, S.-N. Li, Q.-G. Zhai, Y.-C. Jiang, Y. Li, J. Wang, and N. Chen, J. Chem. Therodyn., 41, 1016 (2009).

19. A.S. Alkindi, Y.M. Al-Wahaibi and A.H. Muggeridge, J. Chem. Eng. Data, 53, 2793 (2008).

20. A. Hammadi, J. Chem. Eng. Data, 43, 1004 (1998).

21. S. Magazu, F. Migliardo, N.P. Malomuzh and I.V. Blazhnov, J. Phys. Chem. B, 111, 9563 (2007).

22. J.B. Secur and E. Helen, Eng. Ind. Chem., 43, 2117 (1951).

23. L.A.J. Verhoeye and E. Lauwers, J. Chem. Eng. Data, 14, 306 (1969). 